\title{
RECUENTO DE CÉLULAS SOMÁTICAS EN LECHE CONTAMINADA CON RESIDUOS DE ANTIBIÓTICOS
}

\author{
Somatic Cell Counts in Raw Milk Contaminated With Antibiotic Residues
}

César Ortiz Z. ${ }^{1,2}$, Alfredo Concha U. ${ }^{3}$, Javier Cayro C. ${ }^{3}$

\section{RESUMEN}

El presente estudio tuvo como objetivo evaluar el recuento de células somáticas (RCS) en muestras de leche fresca contaminadas por antibióticos en la cuenca de Arequipa. Se recolectó 1814 muestras de leche en la estación de verano del año 2009, de las cuales 59 resultaron contaminadas con antibióticos. Los valores de RCS de las muestras contaminadas se clasificaron en cinco rangos de acuerdo a condiciones fisiológicas y requisitos de calidad de la leche fresca. El promedio del RCS fue de $1520 \pm 1173$ x $10^{3}$ células $/ \mathrm{ml}$, habiendo diferencias significativas entre rangos $(\mathrm{p}<0.01)$.

Palabras clave: antibióticos, leche, RCS, mastitis, subclínica, Arequipa

\section{Abstract}

The objective of the present study was to evaluate the somatic cell count (SCC) in raw milk samples contaminated with antibiotics in Arequipa milkshed. A total of 1814 were collected in summer 2009, and 59 of them resulted contaminated with antibiotics. SCC values from contaminated samples were stratified in five levels according to physiological status and milk quality requirements. The average SCC was $1520 \pm 1173$ x $10^{3} \mathrm{cel} / \mathrm{ml}$. Significant differences were found between levels of SCC $(\mathrm{p}<0.01)$.

Key words: antibiotics, milk, SCC, mastitis, subclinical, Arequipa

\footnotetext{
${ }^{1}$ Departamento de Campo, ${ }^{3}$ Control de Calidad, Gloria S.A., Arequipa

${ }^{2}$ E-mail: cesarortiz74@hotmail.com
} 
Hay una creciente preocupación en temas concernientes a la salud pública, así como en la seguridad e inocuidad de los alimentos; entre ellos, el tema de la calidad de la leche. Asimismo, el crecimiento de los mercados a nivel mundial y la globalización hace necesario alcanzar los más estrictos requerimientos de calidad, en el orden de mantenerse y progresar en el mercado lácteo (van Schaik et al., 2002).

La leche adulterada con residuos de antibióticos constituye, como tal, un grave riesgo para la salud pública. Por ejemplo, los $\beta$-lactámicos, rutinariamente empleados en el tratamiento del ganado con mastitis, son identificados como alergenos para los humanos (Saville et al., 2000); asimismo, el 5-10\% de la población es hipersensible a la penicilina, presentando reacciones alérgicas cuando ingieren concentraciones de $1 \mathrm{ppb}$ (Nero et al., 2007). En el mismo sentido, la necesidad de reducir la posibilidad de emergencia de microorganismos antibiótico-resistentes, ha resultado en un efectivo y extenso programa de vigilancia para la detección de residuos de antibióticos en la leche (Ruegg y Tabone, 2000; Sawant et al., 2005).

Estudios previos en el Perú demuestran la presencia de varias familias de antibióticos cuyos residuos contaminan la leche fresca (Ortiz et al., 2008). A pesar del riesgo de estos metabolitos, la Norma Técnica Peruana referente a la leche cruda no considera explícitamente este parámetro entre sus indicadores de calidad (INDECOPI, 2003), posiblemente debido a la reducida publicación científica existente en el medio al respecto. Asimismo, se desconoce el grado en que las afecciones sanitarias del ganado, $y$ en especial la mastitis, facilitan la presencia de residuos de antibióticos en la leche, y su relación con otros parámetros de la calidad. Por esto, el objetivo del presente trabajo fue caracterizar el recuento de células somáticas (RCS) en muestras de leche contaminadas con antibióticos.
El estudio se llevó a cabo durante el verano del 2009, en las instalaciones de la Planta de Majes de la empresa Gloria S.A. ubicada en el Alto Siguas, distrito de Majes, provincia de Caylloma en Arequipa, Perú.

Se recolectó muestras de leche fría (200 $\mathrm{ml}$ ) de los tanques cisternas isotérmicos procedentes de los establos lecheros $(n=70)$ de la cuenca de Arequipa. Las muestras se analizaron con el test cualitativo Delvotest ${ }^{\circledR}$ SPNT (DSM, Holanda), el cual contiene esporas de Bacillus stearothermophilus var. calidolactis para determinar la presencia de sustancias inhibidoras en las muestras de leche, incluyendo las sulfamidas. En el caso de muestras positivas a antibióticos y que proviniera de tanques cisternas cuya carga correspondía al recojo de dos o más establos, se procedió a analizar las muestras individuales extraídas durante el recojo para determinar el origen de la contaminación.

Las muestras positivas a residuos de antibióticos fueron reanalizadas con el equipo electrónico De Laval Cell Counter (De Laval, Suecia), el cual registra mediante un sistema óptico luminoso la emisión de luz fluorescente roja de los núcleos celulares teñidos con ioduro de propidio para determinar el recuento de células somáticas (RCS).

Los valores de RCS (en miles) obtenidos se clasificaron en 5 rangos, definidos según las condiciones fisiológicas de salud mamaria y los requisitos nacionales e internacionales: RCS <200 (fisiológicamente normal); $200<$ RCS < 400 (requisito para productos lácteos vendidos en EE.UU.); $400<$ RCS < 500 (límite máximo en la Norma Técnica Peruana); $500<$ RCS $<750$ (límite máximo de aceptación en EE.UU.); >750 (Rechazo de la leche [van Schaik et al., 2002; INDECOPI, 2003; Sargeant et al., 1998]).

Se comparó las proporciones obtenidas según los rangos establecidos mediante la 
Cuadro 1. Estadística descriptiva del recuento de células somáticas (RCS - células x $10^{3} / \mathrm{ml}$ ) de muestras de leche positivas a residuos de antibióticos

\begin{tabular}{lccccc}
\hline & $<200$ & $200-400$ & $400-500$ & $500-750$ & $>750$ \\
\hline $\begin{array}{l}\text { Proporción de casos } \\
\text { positivos }\end{array}$ & $1 / 59$ & $10 / 59$ & $5 / 59$ & $4 / 59$ & $39 / 59$ \\
Promedio (RCS) & 188.0 & 324.8 & 475.4 & 666.3 & 2082.4 \\
Desv. estándar (RCS) & & 65.8 & 209.1 & 104.3 & 1062.7 \\
\hline
\end{tabular}

prueba de Chi-cuadrado para más de dos proporciones, utilizando el software MINITAB ${ }^{\circledR}$ Release 14.12.0.

\section{Resultados}

Se recolectó 1814 muestras de leche, de las cuales 59 estuvieron contaminadas con antibióticos (3.3\%). El promedio obtenido para el recuento de células somáticas en estas muestras fue de $1520 \pm 1173 \times 10^{3}$ células/ml. Las frecuencias de valores de RCS fueron estadísticamente diferentes entre rangos ( $\mathrm{p}<0.01$, Cuadro 1$)$.

\section{Discusión}

Los resultados del estudio indicaron un elevado valor del RCS dentro del grupo de muestras de leche de vaca positivas a antibióticos de la cuenca de Arequipa. En estudios llevados a cabo en la zona de estudio en la misma época del año, se observó un valor máximo de $786 \pm 478 \times 10^{3} \mathrm{cel} / \mathrm{ml}$ (Ortiz y Vera, 2006), lo que indica una alta prevalencia de mastitis (Ruegg y Tabone, 2000) en los establos con muestras de leche contaminadas. Sin embargo, solo el 3.25\% de las muestras resultó contaminada, y de estas, el 72.8\% presentaron niveles de RCS fuera de los valores aceptados por las normas técnicas nacionales (INDECOPI, 2003).
Allison (1985) menciona el tratamiento intramamario en vacas en lactación o durante el periodo seco como la principal causa de contaminación de la leche, lo cual es compatible con las observaciones del presente estudio.

La relación entre un elevado RCS y la contaminación de la leche con antibióticos ha sido descrita previamente en EE.UU. (Ruegg y Tabone, 2000; Saville et al., 2000) y Canadá (Sargeant et al., 1998). En el presente estudio, se encontró que la probabilidad de contaminación con residuos de antibióticos en muestras con un RCS $>750 \times 10^{3} \mathrm{cel} / \mathrm{ml}$ fue 39 veces superior que en el rango de $<200 \mathrm{x}$ $10^{3} \mathrm{cel} / \mathrm{ml}$. Es claro que un elevado RCS es un indicador de una pobre calidad de leche (van Schaik et al., 2002), y por lo tanto un insumo inaceptable para el procesamiento industrial de acuerdo a la normatividad peruana (INDECOPI, 2003).

\section{Literatura CitTadA}

1. Allison JRD. 1985. Antibiotic residues in milk. Br Vet J 141: 121-124.

2. INDECOPI. 2003. Norma Técnica Peruana NTP 2002.001 Leche y productos lácteos. Leche cruda. Requisitos. $4^{\mathrm{a}} \mathrm{ed}$. Lima: INDECOPI.

3. Nero LA, Mattos M, Beloti V, Barros MA, Franco B. 2007. Resíduos de antibióticos em leite cru de quatro regiões leiteiras no Brasil. Cienc Tecnol Aliment 27(2): 391-393. 
4. Ortiz C, Vera R. 2006. Comportamiento del recuento de células somáticas (RCS) en la irrigación de Majes Arequipa. Bol Lima 146: 141-146.

5. Ortiz C, Vera R, Cayro J. 2008. Frecuencia de $\beta$-lactámicos y tetraciclinas en leche fresca en la cuenca de Arequipa. Rev Inv Vet, Perú 19(2): 140-143.

6. Ruegg PL, Tabone TJ. 2000. The relationship between antibiotic residue violations and somatic cell counts in Wisconsin dairy herds. J Dairy Sci 83: 2805-2809.

7. Sargeant JM, Schukken YH, Leslie KE. 1998. Ontario bulk milk somatic cell count reduction program: Progress and outlook. J Dairy Sci 81: 1545-1554.

8. Saville WJA, Wittum TE, Smith KL. 2000. Association between measures of milk quality and risk of violative antimicrobial residues in grade A raw milk. JAVMA 217: 541-545.

9. Sawant AA, Sordillo LM, Jayarao BM. 2005. A survey on antibiotic usage in dairy herds in Pennsylvania. J Dairy Sci 88: 2991-2999.

10. van Shaik G, Lotem M, Schukken YH. 2002. Trends in somatic cell counts, bacterial counts and antibiotic residue violations in New York State during 19992000. J Dairy Sci 85: 782-789. 